\title{
Evaluating spatial changes of human disturbances and their effects on rivers' environmental quality on The Loess Plateau, China
}

\author{
Li Ji ${ }^{1}$, Li Yuan ${ }^{1}$, Wujuan $\mathrm{Mi}^{2}$, Shulian $\mathrm{Xie}^{3}$, and Yonghong $\mathrm{Bi}^{2}$ \\ ${ }^{1}$ Taiyuan University of Science and Technology \\ ${ }^{2}$ Chinese Academy of Sciences \\ ${ }^{3}$ Shanxi University
}

September 25, 2021

\begin{abstract}
Global economic development and population increase public concerns about the sustainable use of water resources. As one of the main drivers of landscape change, human disturbance is altering rivers' hydrochemical indices and trophic states. Studying the relationship between human disturbances and river' status is of significance for regional water conservation and ecosystem safety. In this study, we created a quantitative model to explore the correlation between human disturbance and rivers' status using remote sensing data, measured hydrochemical indices, and the concept of hemeroby index (HI). The results indicated that the river's status including hydrochemical indices and trophic states both had a significant negative correlation with HI $(\mathrm{p}<0.05)$. The river's status in regions was relatively sensitive to the changes of completely disturbed land-use types, such as urban and industrial land. This paper provides additional spatial information and evidence for the relationship between anthropogenic activities and the river environment. The findings may be helpful for policymakers to make strategic decisions of water resources management and land-use planning in an arid area of China.
\end{abstract}

\section{Hosted file}

HP-Manuscript.docx available at https : //authorea.com/users/436330/articles/538724-evaluatingspatial-changes-of-human-disturbances-and-their-effects-on-rivers-environmental-qualityon-the-loess-plateau-china

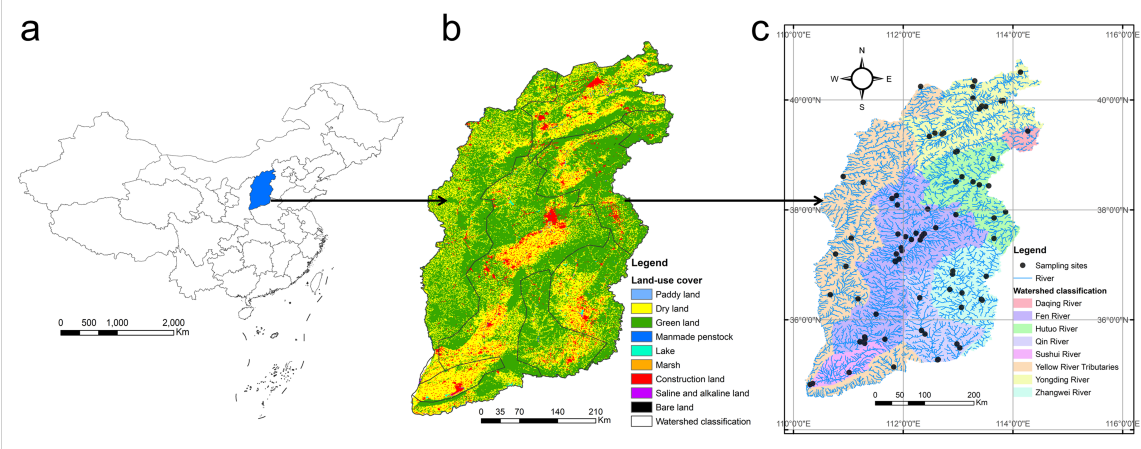



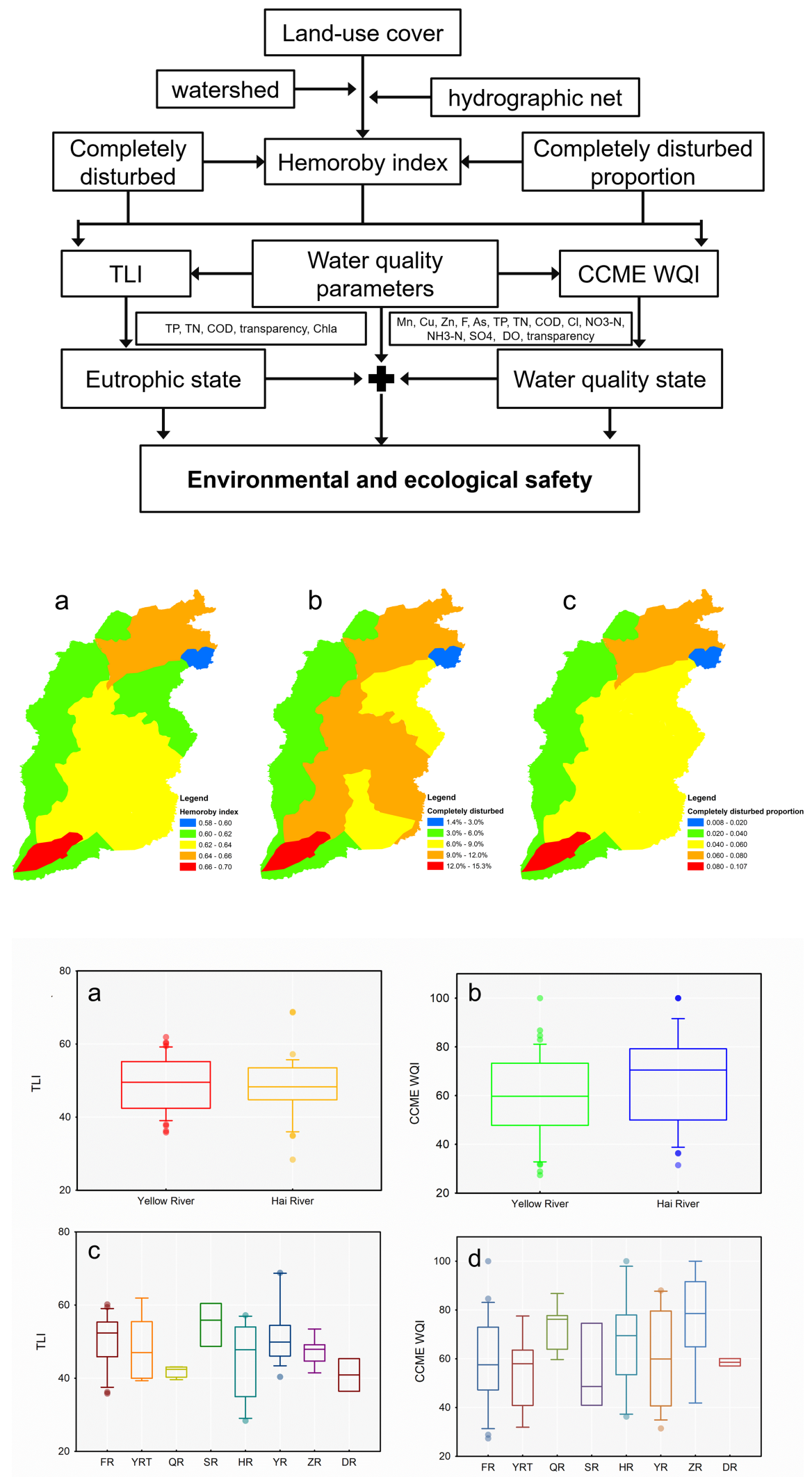

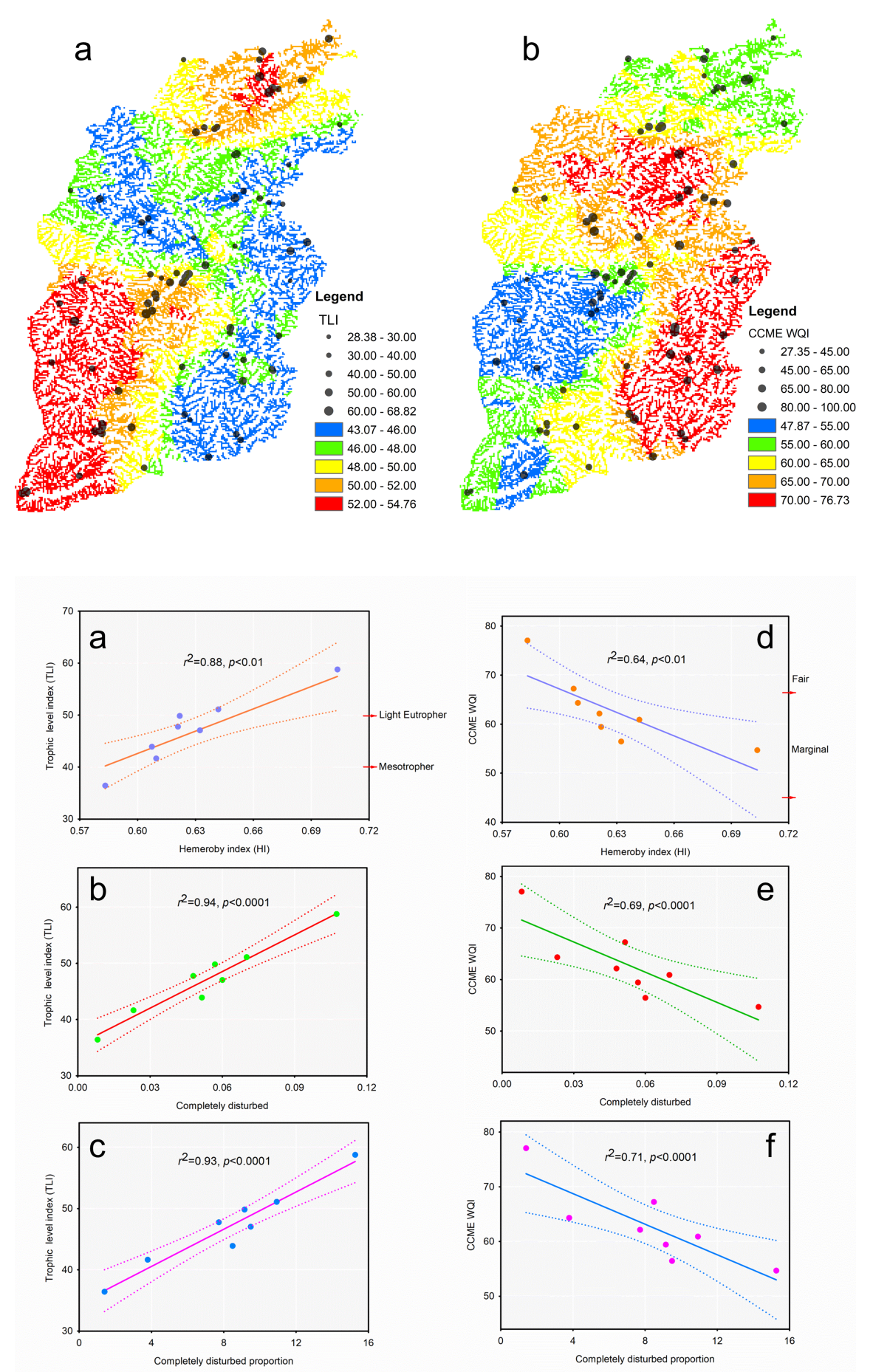
a

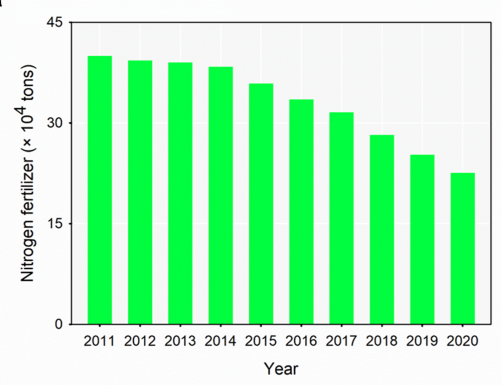

b

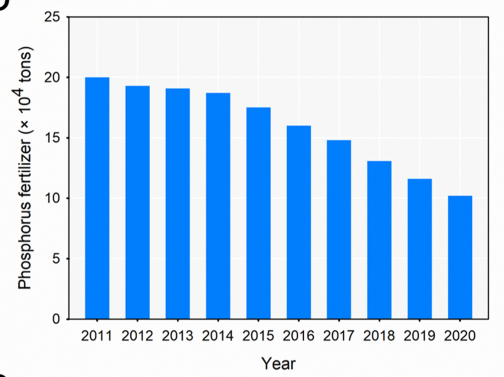

C

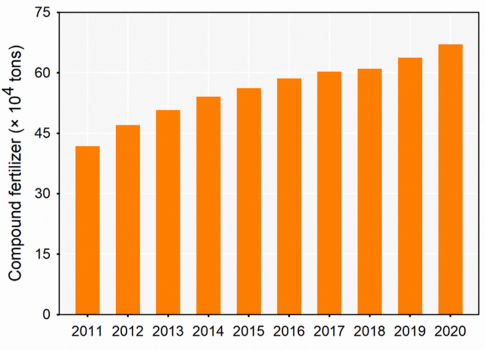

d

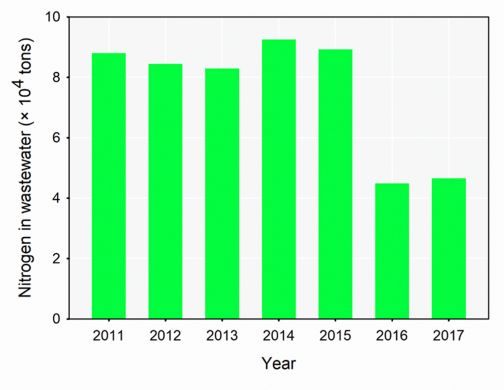

e

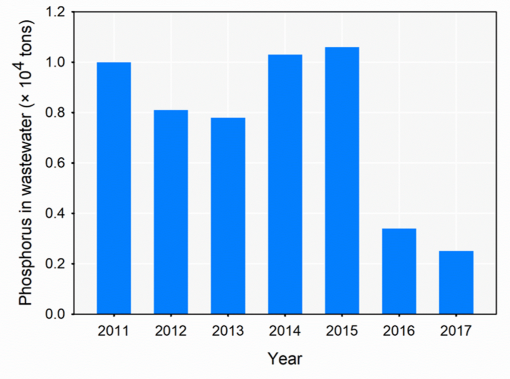

f

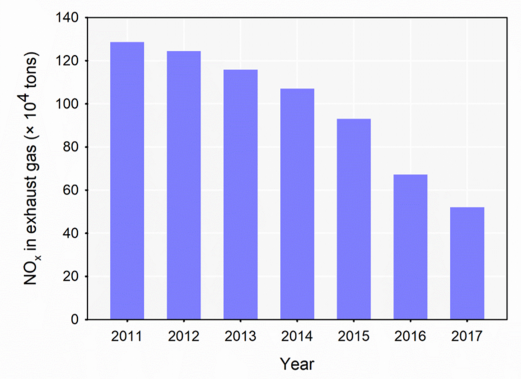

